\title{
A MODIFIED PROCEDURE TO EVALUATE EARTHQUAKE-INDUCED DISPLACEMENT OF SLOPES CONTAINING A WEAK LAYER
}

\author{
Jianliang Deng $^{\text {i) }}$, Yukika Tsutsumi ${ }^{\text {ii) }}$, Hiroshi Kameya ${ }^{\text {iii) }}$ and Junichi Koseki ${ }^{\text {iv) }}$
}

\begin{abstract}
A procedure based on the Janbu method for slope stability analysis and Newmark's sliding block method for displacement calculation is proposed to evaluate rationally the earthquake-induced displacement of slopes containing a weak layer. In the procedure, the effects of the irregular geometry of the sliding plane and generation of excess pore water pressure in the weak layer which forms partly the sliding plane are considered. In the computation following the proposed procedure, a negative yield seismic coefficient to induce a safety factor of unity can be obtained because of the effect of excess pore water pressure, while the residual displacement can become a finite value because the sliding plane becomes flatter in general after the slope undergoes a large displacement.
\end{abstract}

Key words: earthquake, excess pore water pressure, Janbu method, Newmark's sliding block method, slope stability, weak layer (IGC: E8/E12/E13)

\section{INTRODUCTION}

Since its proposal in 1965, Newmark's sliding block method (Newmark, 1965) and its modified versions have been used extensively to calculate the earthquake-induced sliding displacements in practice (e.g., Richards and Elms, 1979; Whitman, 1990; Wartman et al., 2003; Wartman et al., 2005; RTRI, 2007).

The feature of Newmark's sliding block method is that, when the inertia force induced by an earthquake load is sufficiently large, the safety factor of the slope will become less than unity, causing the slope to start to slide as a rigid block and undergo a permanent displacement.

The procedure of Newmark's sliding block method in its original version is schematically described in Fig. 1. When the ground acceleration exceeds $K_{\mathrm{y}} g$, the product of the yield seismic coefficient $K_{\mathrm{y}}$ to induce a safety factor of unity and the acceleration of gravity $g$, a sliding event will be triggered. The sliding continues until the sliding block has the same velocity as that of the foundation (i.e., the relative velocity of the sliding block becomes zero). Such a sliding event may occur several times during one earthquake. The relative sliding displacement can be calculated by integrating the relative velocity between the sliding block and its foundation.

In the original Newmark method, two assumptions are employed: the assumptions of response as a rigid block and a constant value of $K_{\mathrm{y}}$ during sliding. Some modifica-

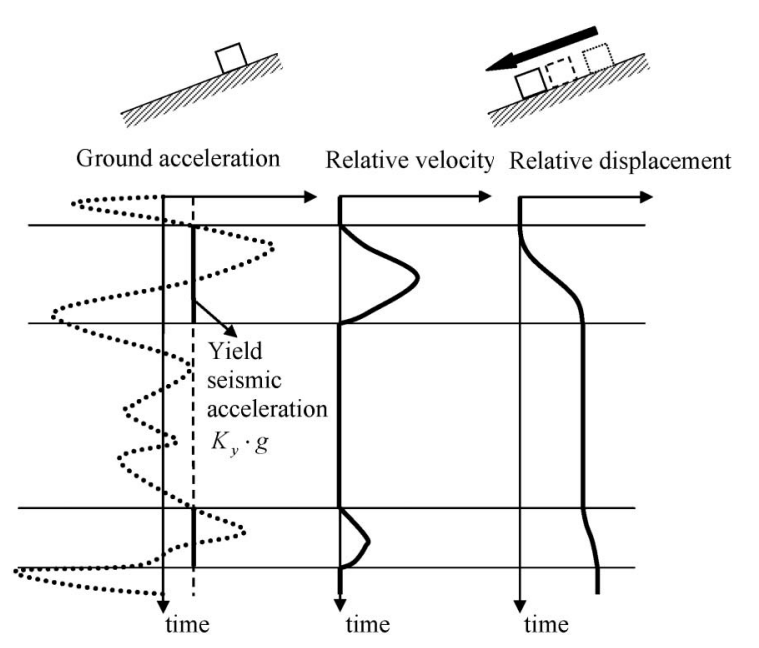

Fig. 1. Newmark's sliding block method

tions were made on the assumption of the rigid block (e.g., Makdisi and Seed, 1978; Rathje and Bray, 2000). Other modifications were also made on the yield seismic coefficient $K_{\mathrm{y}}$. For example, in order to consider the postpeak strain-softening properties of dense granular soils, Okuyama et al. (2003) and Nakajima (2008) calculated the displacements of earthfill dam and retaining wall structures, respectively, using $K_{\mathrm{y}}$ values which decrease with the amount of sliding displacement.

i) JSPS Fellow, Geosphere Research Institute, Saitama University (on leave from Civil Engineering and Mechanics College, Xiangtan University, China).

ii) Institute of Industrial Science, University of Tokyo, Japan.

iii) Energy Business Division, OYO Corporation, Japan.

iv) Institute of Industrial Science, University of Tokyo, Japan (koseki@iis.u-tokyo.ac.jp).

The manuscript for this paper was received for review on July 15, 2009; approved on February 1, 2010.

Written discussions on this paper should be submitted before January 1, 2011 to the Japanese Geotechnical Society, 4-38-2, Sengoku, Bunkyo-ku, Tokyo 112-0011, Japan. Upon request the closing date may be extended one month. 
However, in evaluating the value of $K_{\mathrm{y}}$ to be used in the displacement computation of slopes containing a weak layer (Deng, 2008), two additional issues are worth noting. One is the effect of the irregular geometry of the sliding plane; the other is the effect of excess pore water pressure generation within a saturated weak layer during the earthquake. The sliding plane typically consists of more gentle or flatter conditions on the down slope side, so the shape of the sliding plane to be used in the computation would change with the amount of the sliding displacement. The excess pore water pressure would not dissipate significantly if the sliding movement takes place during the limited duration of the earthquake event. These two issues affect the value of the yield seismic coefficient $K_{\mathrm{y}}$.

In view of the above, this study aims to propose a modified procedure to evaluate more rationally the earthquake-induced displacement of slopes containing a weak layer. First, the original Newmark method (denoted as original NM method herein) is extended by considering the effect of the irregular geometry of the sliding plane in a simplified manner and that of excess pore water pressure generation within the weak layer on the yield seismic coefficient $K_{\mathrm{y}}$ (denoted as extended NM method). Second, in order to consider the effect of the irregular geometry of the sliding plane in a generalized manner, the extended method is further modified by combining it with the widely employed Janbu method (Janbu, 1957), used for slope stability analysis (denoted as extended NJ method).

\section{EXTENSION OF NEWMARK METHOD}

\section{Outline of Extended NM Method}

The sliding of a single rigid element is studied in the extended NM method by considering the effect of excess pore water pressure and also the effect of the irregular geometry of the sliding plane on yield seismic coefficient $K_{\mathrm{y}}$ and residual displacement. The effect of excess pore water pressure on residual displacement has been considered in recent research (e.g., Sassa et al., 1996; Deng et al., 2007).

In the extended NM method, when the excess pore water pressure exceeds a threshold value, the value of $K_{\mathrm{y}}$ can decrease to be negative. Refer to APPENDIX 1 for the formulation of the $K_{\mathrm{y}}$ value. As will be demonstrated in Case 1 later, such negative $K_{\mathrm{y}}$ value in theory yields an infinite value of the residual displacement. However, by considering the decrease in the slope angle with the accumulation of the sliding displacement, the $K_{\mathrm{y}}$ value can be recovered to be positive, inducing a finite value of residual displacement.

\section{Calculation Example}

Two example cases (Fig. 2) were considered to demonstrate the calculation process in the extended NM method.

The slope in Case 1 is a regular infinite slope, on which a sliding block of a finite width is placed, while in Case 2, the slope is irregular with a flat horizontal plane on its toe located at a horizontal distance of $50 \mathrm{~m}$ from the block

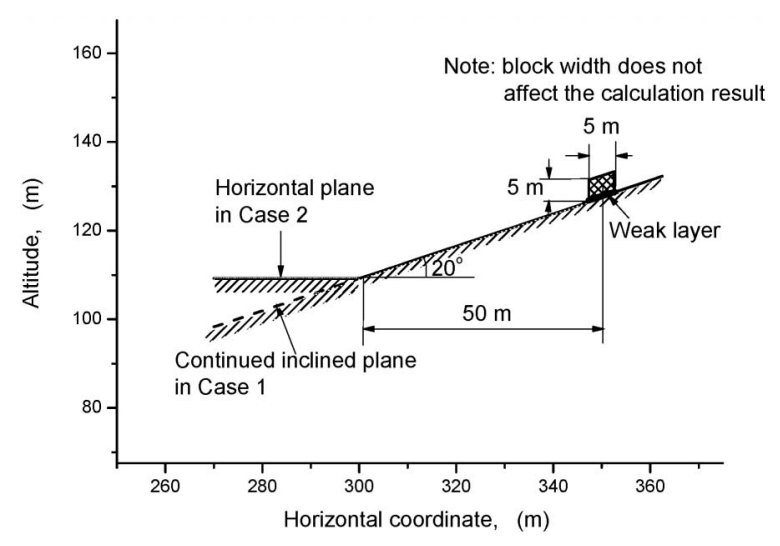

Fig. 2. A block on a slope in Cases 1 and 2

(Fig. 2). Therefore, the effects of the irregular geometry of the sliding plane on the yield seismic coefficient $K_{\mathrm{y}}$ as formulated in Eq. (A11) and residual displacement can be discussed in Case 2.

Both in Cases 1 and 2, a saturated weak layer that partly forms the sliding plane is assumed to exist at the bottom of the sliding block, and the ground water level within the block is set to be $2 \mathrm{~m}$ above the sliding plane. For simplicity, the excess pore water pressure ratio $R_{\mathrm{u}}$ of the weak layer is assumed to change from zero to a specified value immediately after a certain moment $(t=17.42 \mathrm{~s})$ when the ground acceleration exceeds $0.25 \mathrm{~g}$ and to be kept constant until the end of sliding. Here, $R_{\mathrm{u}}=\Delta u / \sigma_{0}^{\prime}$ is the ratio of excess pore water pressure $\Delta u$ to the initial effective stress $\sigma_{0}^{\prime}$.

The value of $R_{\mathrm{u}}$ to be used for the practical application of the proposed procedure would be evaluated based on relevant laboratory cyclic loading tests on the samples retrieved from the concerned slope (e.g., Deng et al., 2007). Otherwise, empirical methods using the relationship between the $R_{\mathrm{u}}$ value and the liquefaction resistance factor (e.g., JGS 1998) could be also employed, while the effect of initial shear stress mobilized within the weak layer on its properties of excess pore water pressure generation needs further studies.

In the calculation, the block is regarded as a single rigid element of density $\rho=1.73 \mathrm{~g} / \mathrm{cm}^{3}$. The density of pore water $\rho_{\text {water }}$ is set to be $1.0 \mathrm{~g} / \mathrm{cm}^{3}$. The assumed values for the other parameters are listed in Table 1.

As the input ground acceleration, a strong motion record at Ojiya Station (EW component) in the 2004 Niigata-ken Chuetsu Earthquake in Japan (NIED, 2004) is employed, as shown in Fig. 3. The time interval of ground acceleration history is 0.01 second.

A comparison of the residual displacement calculation results in Case 1 and Case 2 is made in Fig. 4.

Figure 4 shows that the effect of excess pore water pressure on residual displacement is significant in both Case 1 and Case 2. In Case 2, for $R_{\mathrm{u}}=0$ where the excess pore water pressure is not considered based on the original NM method, the horizontal residual displacement is $1.39 \mathrm{~m}$, while for $R_{\mathrm{u}}=0.6$, the horizontal residual displacement is $70.5 \mathrm{~m}$. 
Table 1. Parameters and calculation results

\begin{tabular}{|c|c|c|c|c|c|c|c|}
\hline \multirow[b]{2}{*}{ Case } & \multicolumn{3}{|c|}{$\begin{array}{c}\text { Strength } \\
\text { parameters }\end{array}$} & \multicolumn{3}{|c|}{ Slope conditions } & \multirow{2}{*}{$\begin{array}{c}\text { Horizontal } \\
\text { residual } \\
\text { displacemen } \\
\text { (m) }\end{array}$} \\
\hline & $c^{\prime}$ & $\phi^{\prime}$ & $R_{\mathrm{u}}^{*)}$ & $\begin{array}{l}\text { Ground } \\
\text { water } \\
\text { level**) } \\
(\mathrm{m})\end{array}$ & $\begin{array}{l}\text { Block } \\
\text { height } \\
(H, \mathrm{~m})\end{array}$ & Slope geometry & \\
\hline Case 1 & \multirow{3}{*}{0} & \multirow{3}{*}{$39^{\circ}$} & \multirow{3}{*}{$\begin{array}{l}0 \sim \\
0.6\end{array}$} & 2 & 5 & $\begin{array}{l}\text { One inclined } \\
\text { plane }\end{array}$ & $1.39 \sim \infty$ \\
\hline Case 2 & & & & 2 & 5 & $\begin{array}{c}\text { One inclined } \\
\text { plane and one } \\
\text { horizontal plane }\end{array}$ & $1.39 \sim 70.5$ \\
\hline Case 3 & & & & 0 & $0 \sim 10.0$ & $\begin{array}{c}\text { One arc plane } \\
\text { and one } \\
\text { horizontal plane }\end{array}$ & $5.3 \sim 75.9$ \\
\hline
\end{tabular}

*) This value is set to be zero before ground motion exceeds $0.25 \mathrm{~g}$.

**) This value is defined as the elevation of the ground water level above the surface of the slope.

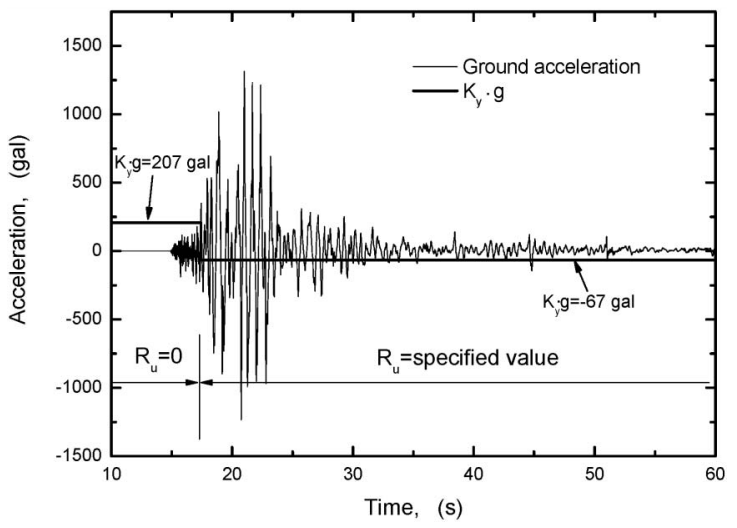

Fig. 3. Time histories of ground acceleration and yield condition in Case 1 (for $\left.R_{\mathrm{u}}=\mathbf{0 . 5 5}\right)$

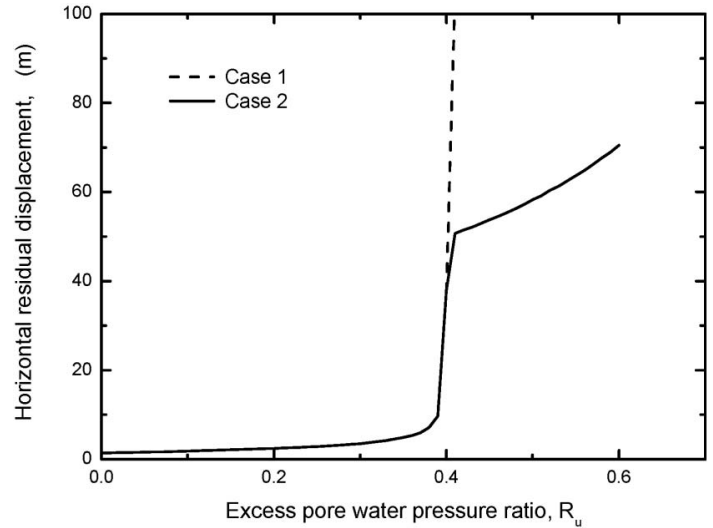

Fig. 4. Relation between $R_{\mathrm{u}}$ and horizontal residual displacement in Cases 1 and 2

Figure 4 also shows that the effect of irregular geometry should be taken into consideration in evaluating a large sliding. For Case 1, the horizontal residual displacement is infinite when $R_{\mathrm{u}}$ exceeds 0.415 . This threshold value corresponds to a condition which yields the value of $K_{\mathrm{y}}$ to be zero (Eq. (A11)). Typical time histories of $K_{\mathrm{y}}$ and

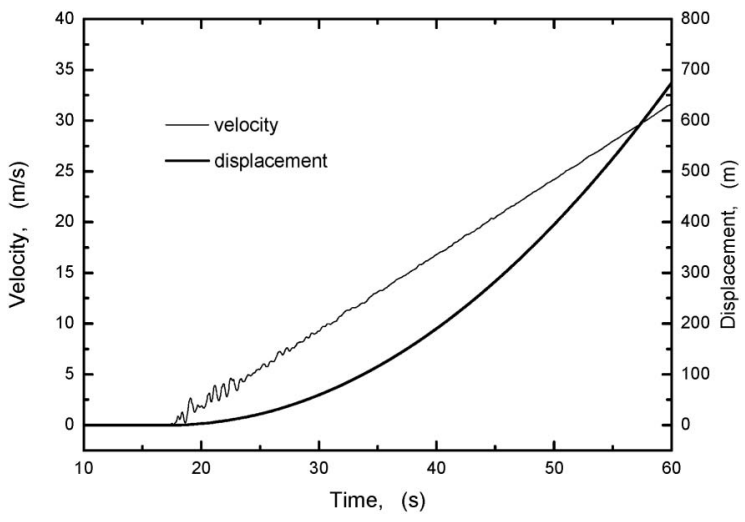

Fig. 5. Time histories of relative velocity and displacement in Case 1 (for $R_{\mathrm{u}}=\mathbf{0 . 5 5}$ )

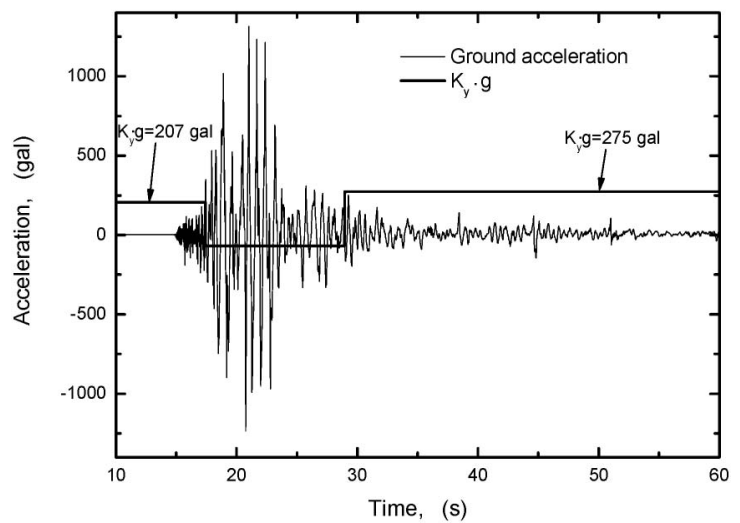

Fig. 6. Time histories of ground acceleration and yield condition in Case 2 (for $R_{\mathrm{u}}=\mathbf{0 . 5 5 )}$

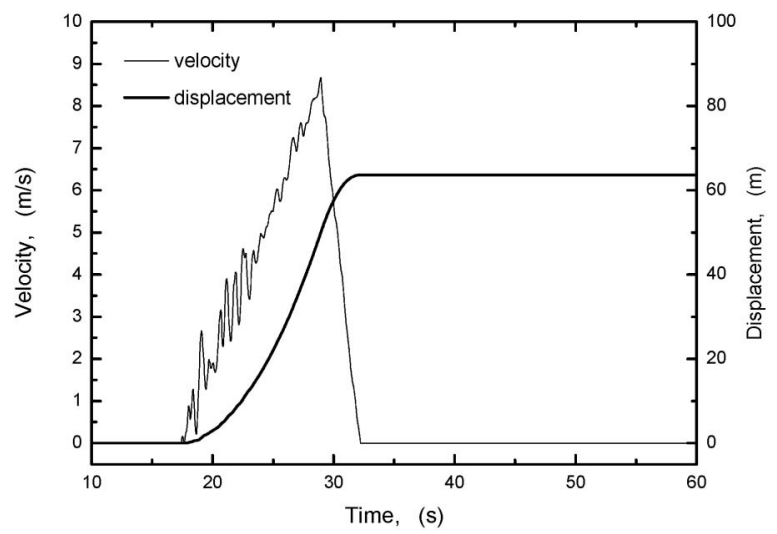

Fig. 7. Time histories of relative velocity and displacement in Case 2

the corresponding horizontal residual displacement (Figs. 3 and 5, for the case of $R_{\mathrm{u}}=0.55$ ) confirm that the negative and constant $K_{\mathrm{y}}$ value could induce a significantly large displacement, which would accumulate into an infinite value of the residual displacement. On the other hand, as the irregular geometry of the sliding plane was considered in the extended NM method (Case 2), the recovery of the $K_{\mathrm{y}}$ value to a positive one could induce a finite value of the horizontal residual displacement as 


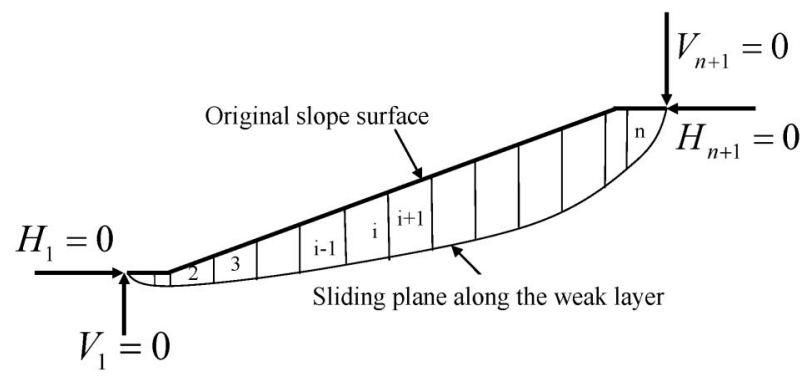

Fig. 8. A slope with vertical slices

typically shown in Figs. 6 and 7 for $R_{\mathrm{u}}=0.55$. When the horizontal displacement exceeds $50 \mathrm{~m}$, the sliding block arrives at the horizontal plane (Fig. 2), yielding the recovery of the $K_{\mathrm{y}}$ value. Thus, the sliding block could finally come to a stop after an additional decelerated moving.

\section{COMBINATION WITH THE JANBU METHOD}

\section{Outline of Extended NJ Method}

In the extended NM method, the sliding mass is simplified as a single rigid block. However, in order to consider a progressive change in the angle of the sliding plane that would take place at the bottom of a relatively long sliding plane, the sliding mass needs to be divided into multiple blocks. In the present study, it was made by employing several vertical slices, as typically shown in Fig. 8, while assuming the following simplified conditions; 1) all the slices share a common horizontal velocity; 2) the slope of each slice base changes with the slope displacement to match the current sliding plane (i.e., the base part of the slice is not rigid); and 3 ) the relative vertical displacement between the adjacent slices is allowable. Thus, a more general and realistic slope could be considered.

First, the value of the yield seismic coefficient $K_{\mathrm{y}}$ is calculated (refer to APPENDIX 2 for the details). Fundamentally, the procedure to calculate $K_{\mathrm{y}}$ is based on the original Janbu method, while a modification is made by considering the effects of the earthquake inertia force and excess pore water pressure. Second, after the $K_{\mathrm{y}}$ value has been obtained, horizontal displacement is obtained by following the procedure of the Newmark method (Fig. 1). Therefore, the above procedure is an extended version of the combination of the Newmark and the Janbu methods (named the extended NJ method).

It should be noted that the angle of sliding plane for each slice may change with the slope displacement. Generally, it induces an increase in the values of the yield seismic coefficient $K_{\mathrm{y}}$ because the sliding plane becomes flatter after undergoing a certain displacement.

\section{Calculation Example}

Calculations of displacement of a finite slope with a horizontal plane at the toe (Case 3) were performed in this section to demonstrate the importance of considering the effects of the irregular geometry of the sliding plane and excess pore water pressure generation within the weak layer on the residual displacement.

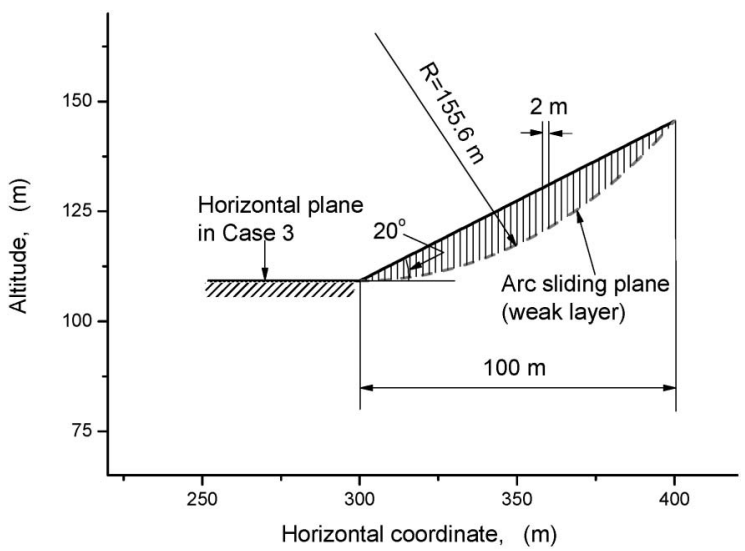

Fig. 9. A slope with existing weak layer in Case 3

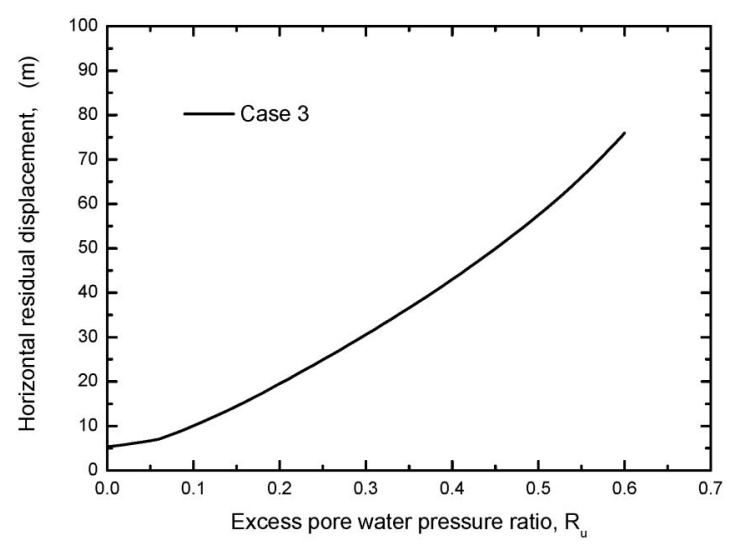

Fig. 10. Relation between $R_{\mathrm{u}}$ and horizontal residual displacement

A slope containing a weak layer in an arc shape is shown in Fig. 9. The sliding is assumed to occur along this existing weak layer.

In Case 3, conditions of the material densities, the input ground acceleration and the assumed values of $R_{\mathrm{u}}$ are set to be the same as those in Case 1 and Case 2. The ground water level is set at the surface of the slope. The width of the slice is $2 \mathrm{~m}$. The other parameter values are listed in Table 1.

The horizontal residual displacements in Case 3 are shown in Fig. 10. The effect of $R_{\mathrm{u}}$ on the residual displacement is very significant. For the case of $R_{\mathrm{u}}=0$, where the excess pore water pressure is not generated, the horizontal displacement is $5.3 \mathrm{~m}$; while for the case of $R_{\mathrm{u}}$ $=0.6$, the horizontal residual displacement is as large as $75.9 \mathrm{~m}$.

It should be noted that, by considering the effect of the irregular geometry of the sliding plane, finite values of the residual displacements could be also obtained in Case 3.

For example, for the case of $R_{\mathrm{u}}=0.55$, even though the yield seismic coefficient $K_{\mathrm{y}}$ becomes a negative value temporarily, it will increase gradually to be positive (Fig. 11), because the sliding plane has an irregular geometry and the horizontal plane at the slope toe can serve as a brake. Therefore, the residual displacement is finite, as shown in Fig. 12. 


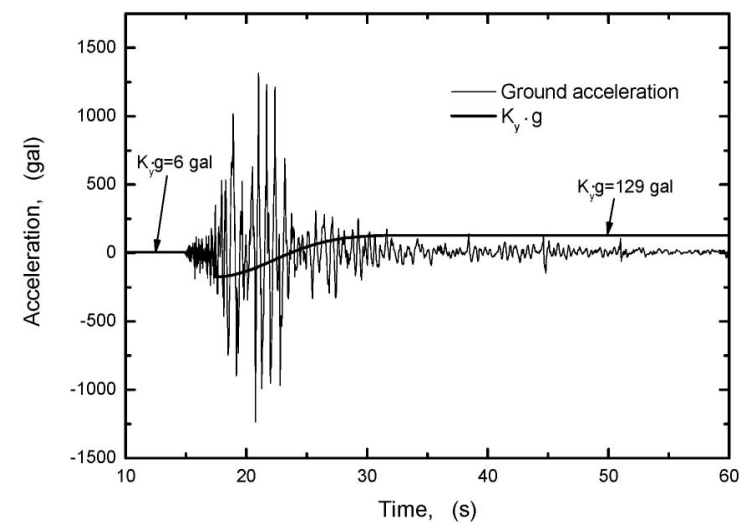

Fig. 11. Time histories of ground acceleration and yield condition in Case 3 (for $\left.R_{\mathrm{u}}=\mathbf{0 . 5 5}\right)$

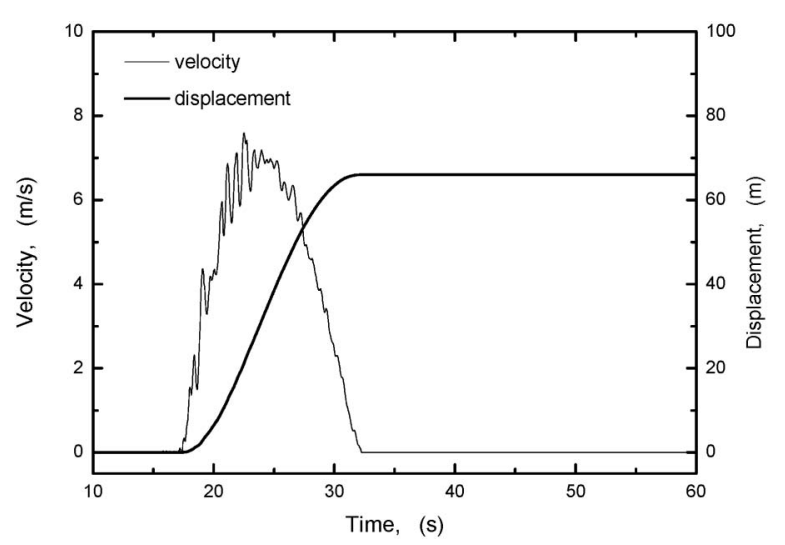

Fig. 12. Time histories of relative velocity and displacement in Case 3 (for $\left.R_{\mathrm{u}}=\mathbf{0 . 5 5}\right)$

\section{CONCLUSIONS}

In order to evaluate the earthquake-induced residual displacement of slopes containing a weak layer as a sliding plane, a modified procedure was proposed by combining the Janbu method for slope stability analysis and Newmark's sliding block method for displacement computation. In the proposed method, the sliding mass is divided into several vertical slices, and all the slices are assumed to share a common horizontal velocity. It has the following advantages over the original Newmark's sliding block method.

1) The effects of excess pore water pressure generation along the sliding plane can be considered. Thus, the proposed method can simulate possible reduction in the yield seismic coefficient before and/or during the sliding process.

2) The effect of irregular geometry of the sliding plane, which typically consists of more gentle or flat condition on the downslope side, can be considered. Thus, the proposed method can yield a finite amount of residual displacement even when the yield seismic coefficient is reduced temporarily to negative values before and/or during the sliding process.

\section{ACKNOWLEDGMENTS}

This study was conducted as a part of the research on "Earthquake damage in active-folding areas: Creation of a comprehensive data archive for remedial measures for civil-infrastructure systems" that is supported by Special Coordination Funds for Promoting Science and Technology of Japan Ministry of Education, Culture, Sports, Science and Technology. The authors are also grateful to Japan Society for the Promotion of Science for the fellowship (ID No. P08391) supporting this research. The first author thanks Japan International Cooperation Agency (JICA) for the financial support during his Ph.D. course at the University of Tokyo.

\section{NOTATION}

$\alpha$ : slope of the base

$\alpha_{\mathrm{i}}$ : average slope of the base of slice $i$

$b_{\mathrm{i}}$ : width of slice $i$

$\Delta h_{\mathrm{i}}$ : difference between $h_{\mathrm{i}}$ and $h_{\mathrm{i}+1}$ of slice $i$

$\Delta H_{\mathrm{i}}$ : difference between two horizontal interslice forces on slice $i$

$\Delta U$ : resultant force due to excess pore water acting on the block base

$\Delta U_{\mathrm{i}}$ : resultant force due to excess pore water acting on the base of slice $i$

$\Delta u$ : excess pore water pressure on the block base

$\Delta u_{\mathrm{i}}$ : excess pore water pressure on the base of slice $i$

$h_{\mathrm{i}}, h_{\mathrm{i}+1}$ : parameter for location of $H_{\mathrm{i}}, H_{\mathrm{i}+1}$ respectively

$H_{\mathrm{i}}, H_{\mathrm{i}+1}$ : horizontal interslice forces on two sides of the slice $i$

$H_{\mathrm{w}}$ : distance between ground water level and sliding plane

$H_{\text {wi }}$ : distance between ground water level and sliding plane in slice $i$

$K_{\mathrm{y}}:$ yield seismic coefficient

$l$ : length of block on its base

$l_{\mathrm{i}}$ : length of slice $i$ on its base

$l_{\mathrm{N}_{\mathrm{i}}}$ : parameter for location of $N_{\mathrm{i}}$

$N$ : resultant force due to initial effective normal stress acting on the block base

$N_{\mathrm{i}}$ : resultant force due to initial effective normal stress acting on the base of the slice $i$

$\rho$ : density of soil

$\rho_{\text {water }}$ : density of water

$R_{\mathrm{u}}$ : excess pore water pressure ratio

$S$ : shear force on the block base

$S_{\mathrm{i}}$ : shear force on the base of the slice $i$

$\sigma_{0}^{\prime}$ : initial effective stress on the block base

$\sigma_{i 0}^{\prime}$ : initial effective stress on the base of slice $i$

$u$ : pore water pressure on the block base

$u_{\mathrm{i}}$ : pore water pressure on the base of slice $i$

$U$ : resultant force due to static pore water pressure acting on the block base

$U_{\mathrm{i}}$ : resultant force due to static pore water pressure acting on the base of slice $i$

$W$ : weight of block

$W_{\mathrm{i}}$ : weight of soil slice $i$ 
$V_{\mathrm{i}}, V_{\mathrm{i}+1}:$ tangential interslice forces on two sides of the slice $i$

$z$ : height of block

$z_{\mathrm{i}}$ : height of slice $i$

\section{REFERENCES}

1) Deng, J. L., Tsutsumi, Y., Kameya, H., Sato, T. and Koseki, J. (2007): Strength properties of undisturbed samples retrieved from failed slope due to earthquake, Proc. 9th International Summer Symposium, JSCE, Yokohama, 159-162.

2) Deng, J. L. (2008): Case studies on the mechanism of earthquakeinduced failure of dip slopes containing a weak layer, Doctor thesis, the University of Tokyo.

3) Janbu, N. (1957): Earth pressures and bearing capacity calculations by generalized procedure of slices, Proc. 4th International Conference on Soil Mechanics and Foundation Engineering, 2, 207-212.

4) Japanese Geotechnical Society (1998): Remedial measures against soil liquefaction-from Investigation and Design to Implementation-, Balkema, 58-59.

5) Japanese Geotechnical Society (2006): An introduction to analyses on slope stability and deformation: from The Basic to Engineering Practice, JGS, 34-36 (in Japanese).

6) Makdisi, F. I. and Seed, H. B. (1978): Simplified procedure for estimating dam and embankment earthquake-induced deformations, Journal of the Geotechnical Engineering Division, ASCE, 104(7), 849-867.

7) Nakajima, S. (2008): Development of procedures to evaluate residual displacements of retaining walls under seismic loading considering deformation properties of subsoil and backfill, Doctor thesis, the University of Tokyo (in Japanese).

8) National Research Institute for Earth Science and Disaster Prevension of Japan (NIED) (2004): http://www.k-net.bosai.go.jp/k-net/ quake/

9) Newmark, N. M. (1965): Effects of earthquakes on dams and embankments, Géotechnique, 15(2), 139-160.

10) Okuyama, Y., Yoshida, T., Tatsuoka, F., Koseki, J., Uchimura, T., Sato, N. and Oie, M. (2003): Shear banding characteristics of granular materials and particle size effects on the seismic stability of earth structures, Proc. 3rd Int. Sym. on Deformation Characteristics of Geomaterials, IS Lyon 03 (eds. by Di Benedetto et al.), Balkema, September, 607-616.

11) Railway Technical Research Institute (RTRI) (2007): Design Standards for Railway Structures and Commentary (Earth Structures), 413-417 (in Japanese).

12) Rathje, E. M. and Bray, J. D. (2000): Nonlinear coupled seismic sliding analysis of earth structures, Journal of Geotechnical and Geoenvironmental Engineering, 126(11), 1002-1014.

13) Richards, R. and Elms, D. G. (1979): Seismic behavior of gravity type retaining walls, Journal of Geotechnical Engineering, ASCE, 105(4), 449-469.

14) Sassa, K., Fukuoka, H., Scarascia-Mugnozza, G. and Evans, S. (1996): Earthquake-induced landslides: distribution, motion and mechanisms, Soils and Foundations, Special Issue on Geotechnical Aspects of the January 171995 Hyogoken-Nambu Earthquake, 53-64.

15) Wartman, J., Bray, J. D. and Seed, R. B. (2003): Inclined plane studies of the Newmark sliding block procedure, Journal of Geotechnical and Geoenvironmental Engineering, 129(8), 673-684.

16) Wartman, J., Seed, R. B. and Bray, J. D. (2005): Shaking table modeling of seismically induced deformations in slopes, Journal of Geotechnical and Geoenvironmental Engineering, 131(5), 610-622.

17) Whitman, R. V. (1990): Seismic design and behavior of gravity retaining walls, Proc. A Conference on Design and Performance of Earth Retaining Structures (eds. by P. C. Lambe and A. Hansen), ASCE, Cornell University, 817-842.

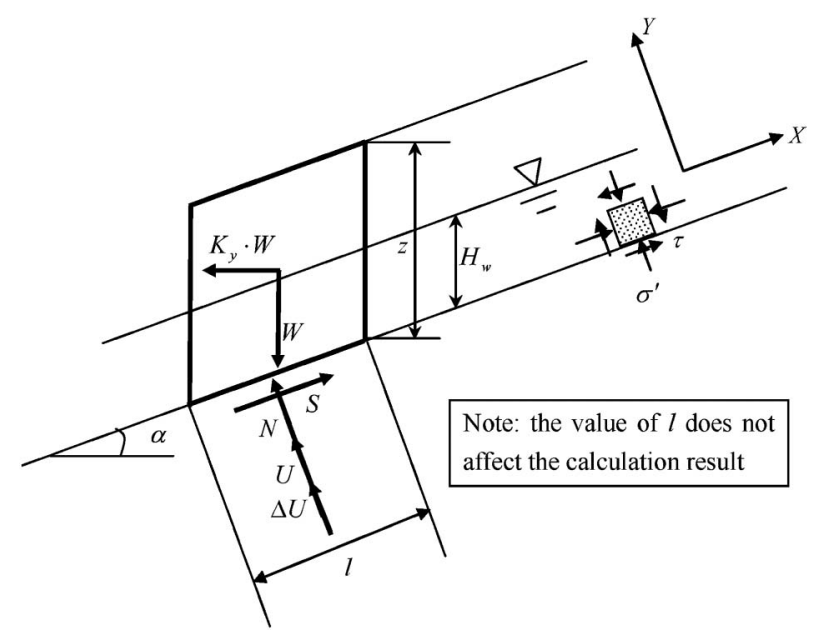

Fig. A1. A single block on a slope

\section{APPENDIX 1: CALCULATION OF $K_{\mathrm{y}}$ IN EXTENDED NM METHOD}

A single block on a slope as shown in Fig. A1 is considered. Definitions of notations in Fig. A1 are summarized in the list of notations. The equilibrium equations can be expressed as Eqs. (A1) and (A2):

Y direction:

$$
-W \cdot \cos \alpha+K_{\mathrm{y}} \cdot W \cdot \sin \alpha+N+U+\Delta U=0
$$

$\mathrm{X}$ direction:

$$
-W \cdot \sin \alpha-K_{\mathrm{y}} \cdot \cos \alpha+S=0
$$

The safety factor $F_{\mathrm{s}}$ is defined as

$$
F_{\mathrm{s}}=\frac{c \cdot l+\sigma^{\prime} \cdot \tan \phi^{\prime} \cdot l}{S}
$$

The critical condition to induce the sliding can be expressed by

$$
F_{\mathrm{s}}=\frac{c \cdot l+\sigma^{\prime} \cdot \tan \phi^{\prime} \cdot l}{S}=1
$$

or

$$
S=c \cdot l+\sigma^{\prime} \cdot \tan \phi^{\prime} \cdot l
$$

In Eq. (A3)

$$
\sigma^{\prime}=\sigma-u-\Delta u
$$

where $\sigma$ is total normal stress; $u$ is static water pressure; $\Delta u$ is excess pore water pressure generated during earthquake.

Referring to Eq. (A1), the total stress is evaluated as

$$
\sigma=(N+U+\Delta U) / l=W \cdot\left(\cos \alpha-K_{\mathrm{y}} \cdot \sin \alpha\right) / l
$$

where the total weight $W$ of the block is given as

$$
W=\rho \cdot g \cdot z \cdot l \cdot \cos \alpha
$$

In a similar manner, by considering the effect of horizontal inertia of pore water, the static water pressure is evaluated as 


$$
u=U / l=\rho_{\text {water }} \cdot g \cdot H_{\mathrm{w}} \cdot\left(\cos \alpha-K_{\mathrm{y}} \cdot \sin \alpha\right) \cdot \cos \alpha
$$

The excess pore water pressure is evaluated by introducing the excess pore water pressure ratio $R_{\mathrm{u}}$ defined as

$$
R_{\mathrm{u}}=\Delta u / \sigma_{0}^{\prime}
$$

or

$$
\Delta u=R_{\mathrm{u}} \cdot \sigma_{0}^{\prime}
$$

where $\sigma_{0}^{\prime}$ is the value of effective stress $\sigma^{\prime}$ at a normal state without earthquake.
According to Eq. (A1) while setting $K_{\mathrm{y}}=0$ for the normal state, $\sigma_{0}^{\prime}$ is evaluated as

$$
\sigma_{0}^{\prime}=N_{0} / l=\left(W \cdot \cos \alpha-U_{0}\right) / l
$$

where $N_{0}$ and $U_{0}$ denote for the reaction forces mobilized by the effective stress and pore water pressure, respectively, at the normal state. The value of $U_{0}$ is given as

$$
U_{0}=\rho_{\text {water }} \cdot g \cdot H_{\mathrm{w}} \cdot \cos ^{2} \alpha \cdot l
$$

Thus, by combining Eqs. (A2) through (A10), the yield seismic coefficient can be obtained as

$$
K_{\mathrm{y}}=\frac{c+\rho \cdot g \cdot z \cdot \cos \alpha \cdot\left(\left(1-R_{\mathrm{u}}\right) \cdot \cos \alpha \cdot \tan \phi^{\prime}-\sin \alpha\right)-\rho_{\mathrm{water}} \cdot g \cdot H_{\mathrm{w}} \cdot\left(1-R_{\mathrm{u}}\right) \cdot \cos ^{2} \alpha \cdot \tan \phi^{\prime}}{\rho \cdot g \cdot z \cdot \cos \alpha \cdot\left(\cos \alpha+\sin \alpha \cdot \tan \phi^{\prime}\right)-\rho_{\text {water }} \cdot g \cdot H_{\mathrm{w}} \cdot \sin \alpha \cdot \cos \alpha \cdot \tan \phi^{\prime}}
$$

\section{APPENDIX 2: CALCULATION OF $K_{\mathrm{y}}$ IN EXTENDED NJ METHOD}

It is assumed that the sliding plane is along an existing weak layer (Fig. 8). Thus the procedure to determine the location and the shape of the sliding plane is skipped herein.

\section{Equilibrium Condition}

A typical vertical slice is shown in Fig. A2 with a definition of $\mathrm{X}$ and $\mathrm{Y}$ directions. It is assumed in this study that each slice starts to slide at the same value of $K_{\mathrm{y}}$, so all the slices share the same horizontal velocity and displacement. The definitions of notations employed in Fig. A2 are summarized in the list of notations.

The equilibrium equations of the slice with respect to $\mathrm{Y}$ and $\mathrm{X}$ directions can be expressed as Eqs. (A12) and (A13), respectively.

$$
\begin{aligned}
& -W_{\mathrm{i}} \cdot \cos \alpha+K_{\mathrm{y}} \cdot W_{\mathrm{i}} \cdot \sin \alpha_{\mathrm{i}}+N_{\mathrm{i}}+U_{\mathrm{i}}+\Delta U_{\mathrm{i}} \\
& \quad+\Delta H_{\mathrm{i}} \cdot \sin \alpha_{\mathrm{i}}-\Delta V_{\mathrm{i}} \cdot \cos \alpha_{\mathrm{i}}=0 \\
& -W_{\mathrm{i}} \cdot \sin \alpha-K_{\mathrm{y}} \cdot W_{\mathrm{i}} \cdot \cos \alpha_{\mathrm{i}}+S_{\mathrm{i}}-\Delta H_{\mathrm{i}} \cdot \cos \alpha_{\mathrm{i}} \\
& \quad-\Delta V_{\mathrm{i}} \cdot \sin \alpha_{\mathrm{i}}=0
\end{aligned}
$$

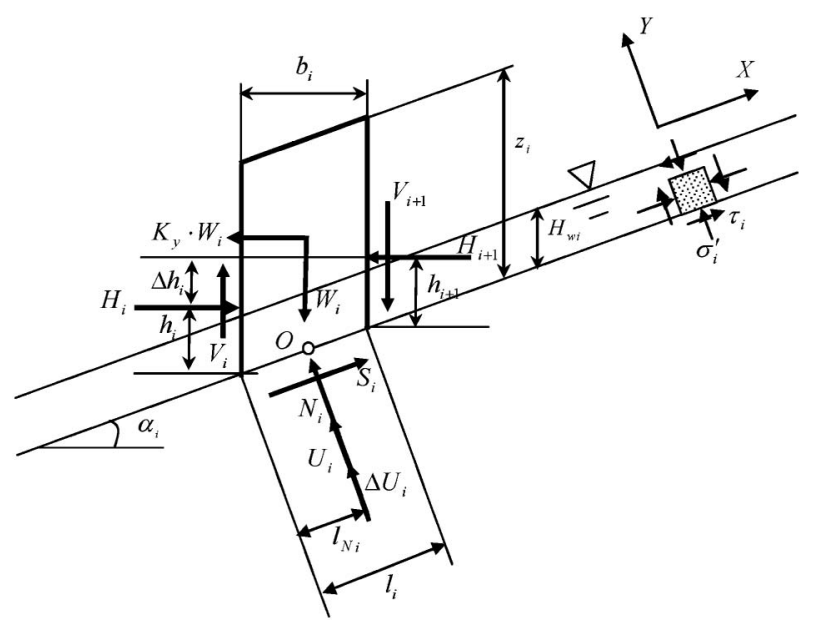

where,

$$
\begin{aligned}
& W_{\mathrm{i}}=\rho \cdot g \cdot z_{\mathrm{i}} \cdot l_{\mathrm{i}} \cdot \cos \alpha_{\mathrm{i}} ; \\
& U_{\mathrm{i}}=\rho_{\text {water }} \cdot g \cdot H_{\mathrm{wi}} \cdot\left(\cos \alpha_{\mathrm{i}}-K_{\mathrm{y}} \cdot \sin \alpha_{\mathrm{i}}\right) \cdot \cos \alpha_{\mathrm{i}} \cdot l_{\mathrm{i}}
\end{aligned}
$$

Accumulation of all the horizontal internal forces shall be zero:

$$
\sum \Delta H_{\mathrm{i}}=0
$$

Moment equilibrium of the slice $i$ can be described as:

$$
\begin{aligned}
& V_{\mathrm{i}} \cdot \frac{b_{\mathrm{i}}}{2}+\left(V_{\mathrm{i}}+\Delta V_{\mathrm{i}}\right) \cdot \frac{b_{\mathrm{i}}}{2}+H_{\mathrm{i}} \cdot\left(h_{\mathrm{i}}-\frac{b_{\mathrm{i}}}{2} \cdot \tan \alpha_{\mathrm{i}}\right) \\
& -\left(H_{\mathrm{i}}+\Delta H_{\mathrm{i}}\right) \cdot\left(h_{\mathrm{i}}+\Delta h_{\mathrm{i}}-\frac{b_{\mathrm{i}}}{2} \cdot \tan \alpha_{\mathrm{i}}\right) \sin \alpha_{\mathrm{i}}-K_{\mathrm{y}} \cdot W_{\mathrm{i}} \cdot \frac{z_{\mathrm{i}}}{2}=0
\end{aligned}
$$

By simplifying the preceding equation for the vertical force $V_{\mathrm{i}}$, Eq. (A16) can be obtained.

$$
V_{\mathrm{i}}=\left(H_{\mathrm{i}} \cdot \Delta h_{\mathrm{i}}+\Delta H_{\mathrm{i}} \cdot h_{\mathrm{i}}+K_{\mathrm{y}} \cdot W_{\mathrm{i}} \cdot \frac{z_{\mathrm{i}}}{2}\right) / b_{\mathrm{i}}
$$

In deriving Eq. (A16), it is assumed that $h_{\mathrm{i}}$ is equal to one third of the height of slice $i$.

As $V_{\mathrm{i}}=0$ is a known condition, Eq. (A16) will not be used for the first slice with $i=1$.

\section{Critical Condition to Induce Sliding}

Assuming the soil property along the slice base to be perfectly plastic described by the Coulomb failure criterion, the local safety factor $F_{\mathrm{si}}$, which is equal to unity under the critical condition, is defined as

$$
F_{\mathrm{si}}=\frac{c_{\mathrm{i}} \cdot l_{\mathrm{i}}+\sigma_{\mathrm{i}}^{\prime} \cdot \tan \phi_{\mathrm{i}}^{\prime} \cdot l_{\mathrm{i}}}{S_{\mathrm{i}}}=1
$$

Normal stress $\sigma_{\mathrm{i}}$, pore water pressure $u_{\mathrm{i}}$ and effective stress $\sigma_{\mathrm{i}}^{\prime}$ can be expressed by Eqs. (A18), (A19) and (A20) respectively.

Fig. A2. Forces acting on a vertical slice 


$$
\begin{aligned}
\sigma_{\mathrm{i}} & =\left(N_{\mathrm{i}}+U_{\mathrm{i}}+\Delta U_{\mathrm{i}}\right) / l_{\mathrm{i}} \\
u_{\mathrm{i}} & =U_{\mathrm{i}} / l_{\mathrm{i}}=\rho_{\text {water }} \cdot g \cdot H_{\mathrm{wi}} \cdot\left(\cos \alpha_{\mathrm{i}}-K_{\mathrm{y}} \cdot \sin \alpha_{\mathrm{i}}\right) \cdot \cos \alpha_{\mathrm{i}} \\
& =A_{1 \mathrm{i}}-A_{2 \mathrm{i}} \cdot K_{\mathrm{y}}
\end{aligned}
$$

where,

$$
\begin{aligned}
& A_{1 \mathrm{i}}=\rho_{\text {water }} \cdot g \cdot H_{\mathrm{wi}} \cdot \cos ^{2} \alpha_{\mathrm{i}}, \\
& A_{2 \mathrm{i}}=\rho_{\text {water }} \cdot g \cdot H_{\mathrm{wi}} \cdot \cos \alpha_{\mathrm{i}} \cdot \sin \alpha_{\mathrm{i}}, \\
& \sigma_{\mathrm{i}}^{\prime}=\sigma_{\mathrm{i}}-u_{\mathrm{i}}-\Delta u_{\mathrm{i}}=N_{\mathrm{i}} / l_{\mathrm{i}}
\end{aligned}
$$

The definition of excess pore water pressure ratio follows the one as has been made by Eq. (A8) for extended NM method. For extended NJ method, it is further assumed that all slices have the same $R_{\mathrm{u}}$ value. So the expression of $R_{\mathrm{u}}$ is:

$$
R_{\mathrm{u}}=\Delta u_{\mathrm{i}} / \sigma_{\mathrm{i} 0}^{\prime}
$$

or

$$
S_{\mathrm{i}}=\frac{1}{m_{\alpha}} \cdot\left[\left(c_{\mathrm{i}}-R_{\mathrm{u}} \cdot \sigma_{\mathrm{i} 0}^{\prime} \cdot \tan \phi_{\mathrm{i}}^{\prime}\right) \cdot b_{\mathrm{i}}+\left(W_{\mathrm{i}}+\Delta V_{\mathrm{i}}-\left(A_{1 \mathrm{i}}-A_{2 \mathrm{i}} \cdot K_{\mathrm{y}}\right) \cdot b_{\mathrm{i}}\right) \tan \phi_{\mathrm{i}}^{\prime}\right]
$$

where, $m_{\alpha}=\cos \alpha_{\mathrm{i}}+\sin \alpha_{\mathrm{i}} \cdot \tan \phi_{\mathrm{i}}^{\prime}$.

By substituting Eq. (A24) into Eq. (A13), expression of $\Delta H_{\mathrm{i}}$ can be deduced:

$$
\Delta H_{\mathrm{i}}=\frac{1}{m_{\alpha} \cdot \cos \alpha_{\mathrm{i}}} \cdot\left[\left(c_{\mathrm{i}}-R_{\mathrm{u}} \cdot \sigma_{\mathrm{i} 0}^{\prime} \cdot \tan \phi_{\mathrm{i}}^{\prime}\right) \cdot b_{\mathrm{i}}+\left(W_{\mathrm{i}}+\Delta V_{\mathrm{i}}-\left(A_{1 \mathrm{i}}-A_{2 \mathrm{i}} \cdot K_{\mathrm{y}}\right) \cdot b_{\mathrm{i}}\right) \tan \phi_{\mathrm{i}}^{\prime}\right]-\left(W_{\mathrm{i}}+\Delta V_{\mathrm{i}}\right) \tan \alpha_{\mathrm{i}}-K_{\mathrm{y}} \cdot W_{\mathrm{i}}
$$

By substituting Eq. (A25) into Eq. (A14), expression of $K_{\mathrm{y}}$ can be obtained:

$$
K_{\mathrm{y}}=\frac{\sum_{\mathrm{i}=1}^{n}\left(\frac{1}{m_{\alpha} \cdot \cos \alpha_{\mathrm{i}}} \cdot\left[c_{\mathrm{i}} \cdot b_{\mathrm{i}}+\left(W_{\mathrm{i}}+\Delta V_{\mathrm{i}}-\left(A_{1 \mathrm{i}}+R_{\mathrm{u}} \cdot \sigma_{\mathrm{i} 0}^{\prime}\right) \cdot b_{\mathrm{i}}\right) \tan \phi_{\mathrm{i}}^{\prime}\right]-\left(W_{\mathrm{i}}+\Delta V_{\mathrm{i}}\right) \tan \alpha_{\mathrm{i}}\right)}{\sum_{\mathrm{i}=1}^{n}\left(W_{\mathrm{i}}-\frac{A_{2 \mathrm{i}} \cdot \tan \phi_{\mathrm{i}}^{\prime} \cdot b_{\mathrm{i}}}{m_{\alpha} \cdot \cos \alpha_{\mathrm{i}}}\right)}
$$

\section{Iteration Procedure to Evaluate the $K_{\mathrm{y}}$ Value}

It needs a process of trial-and-error iteration to find $K_{\mathrm{y}}$ in Eq. (A26). The process which is similar to that used in JGS (2006), involves Eqs. (A25), (A26) and (A16):

1) Assuming $\Delta V_{\mathrm{i}}=0$ in Eq. (A26), substitute other parameters into this equation to find $\left(K_{\mathrm{y}}\right)_{0}$.

2) Substitute $\Delta V_{\mathrm{i}}=0$ and $\left(K_{\mathrm{y}}\right)_{0}$ into Eq. (A25) to find $\Delta H_{\mathrm{i}}$, and calculate horizontal forces $H_{\mathrm{i}}$ on each slice by $H_{\mathrm{i}}=\Sigma \Delta H_{\mathrm{i}-1}$;
3) Substitute $\Delta H_{\mathrm{i}}$ and $H_{\mathrm{i}}$ into Eq. (A16) to calculate $V_{\mathrm{i}}$ if $i \neq 1$, and calculate vertical forces increment $\Delta V_{\mathrm{i}}$ on each slice by $\Delta V_{\mathrm{i}}=V_{\mathrm{i}+1}-V_{\mathrm{i}}$;

4) Substitute all $\Delta V_{\mathrm{i}}$ obtained in step 4) and other parameters into Eq. (A26) to find $\left(K_{\mathrm{y}}\right)_{1}$.

If the difference between $\left(K_{\mathrm{y}}\right)_{1}$ and $\left(K_{\mathrm{y}}\right)_{0}$ is less than the allowable value which is set equal to 0.0001 in this study, $\left(K_{\mathrm{y}}\right)_{1}$ is the yield seismic coefficient; if not, let $K_{\mathrm{y}}=\left(K_{\mathrm{y}}\right)_{1}$ and $\left(K_{\mathrm{y}}\right)_{0}=\left(K_{\mathrm{y}}\right)_{1}$, and iterate from step 2$)$. 